\title{
The Application of Micro Lecture in English Reading Teaching
}

\author{
Sufen $L U^{1, a}$ \\ ${ }^{1}$ Department of Foreign Languages \\ Changsha Medical University, Hunan, Changsha 410219, China \\ a lusufenhn@126.com
}

Keywords: Micro Lecture, English Reading, Teaching, Application

\begin{abstract}
With the development of educational informationization, modern education technology based on multimedia and network has penetrated into all aspects of education and teaching. English reading teaching which plays an important role in English teaching serves as the main way to improve the effectiveness of English teaching. It is influenced by the traditional teaching method for a long time, and there are inevitably some problems in the teaching of reading. In this paper, we combine the characteristics of English reading teaching, explore the application of Micro Lecture in English Reading Teaching, discuss the advantages, disadvantages and the considerations they should pay attention when using Micro Lecture in English teaching, so as to promote the development of English Teaching and improve the students' English reading proficiency.
\end{abstract}

\section{Introduction}

The traditional teaching mode classifies the classroom as the main position of teaching, where teachers crammingly impart knowledge to students in the way of collective teaching whereas during English reading teaching, a lot of words and syntax involved are difficult for students to fully grasp due to the scattered plentiful knowledge. In particular, in the traditional teaching mode, 40 to 50 minutes' classroom teaching contents or output can not be absorbed and repeated mistakes in practice cause students tired thus achieving no effect and their learning enthusiasm is lost.

With the rapid development of network information, WeChat, Weibo, Micro-store and many other kinds of "micro"s have come into people's vision and life. Today, the development of the world has gradually stepped into a Micro Era, so naturally, micro lectures have increasingly become important in English teaching with their characteristics: brief and refined.

\section{Origin and Development of Micro Lecture}

Micro lecture, also called micro course, is recently one big hot spot in modern education. The prototype of Micro lecture dates back to 1993, when an American educator named Le Roy a. McGrew proposed 60-second Courses. And in 1995, a British educator T. P. Kee proposed one-minute lecture. The presently heatedly-discussed Miniature Course originated from the American college of New Mexico in 2008, where David Penrose in SAN Juan College thought its core idea is intimately involving teaching contents into teaching targets to produce a "more-focused learning experience". Hu Tiesheng from Foshan, Guangdong introduced the Micro lecture in 2010 and translated the term into Weike, thereafter, a boom of Micro heat was started domestically ${ }^{[1]}$.

So what is a Micro lecture? In classical teaching academic monographs, a class is described as the following: "Class is an organized teaching process with a time limit. Its function is to achieve a complete, but also limited teaching purpose."'Micro lectures" refer to teaching approaches or procedures that use the videos as the main carrier, which records the teacher's teaching behavior around a certain knowledge including a filmed course, recorded course, copied blackboard writing course, animation course and free combination courses ${ }^{[2]}$. Micro lectures' main composition is composed of videoed classroom teaching clips, teaching design, material courseware, teaching reflection and practice examination and auxiliary teaching resources such as students' feedback and teachers' evaluation,all of which create a certain organized and topic-based small environment. 
Mr Crook, a famous scholar, once argued for reading a lot of English as a major means of English teaching, and in the course syllabus, cultivating the students' ability of reading comprehension is also required to be focused on. Therefore, reading teaching takes a very important position in English teaching.

Reading is the process of cognitive construction of written information, which is a very important component in the process of English learning. Through reading people have access to outside information, so the process of reading is essentially the process of obtaining information ${ }^{[3]}$. In the early 1980s, Karur put forward the " schema theory", on the basis of which people will be involved in the reading teaching pattern and divide it into content schema and form schema. Content schema refers to the reader's understanding of the text, namely the background knowledge in a narrow sense; and form schema refers to the readers' degree of mastering the text layout arrangement, namely generalized sense of knowledge. The theory fully revealed the nature of reading, emphasizing the essence of reading is the reader's background knowledge and the interaction process of text messages while reading materials.

\section{Problems Existent in English Reading Teaching}

Reading habits, emotions, skills, strategy and many other factors may affect reading. In the past, because we haven't fully understood that reading is the concept of social activity, there are some problems in the teaching, mainly embodied in the following aspects:

A.The teacher is the center of the classroom --- Teachers dominate the class, so students can only passively accept what the teacher conveys in the class.

B.Too much emphasis is laid on grammar in reading teaching --- Teachers just treat reading as intensive reading: reading the new words, interpreting the words, listing collocations, analyzing original texts word for word. Some teachers even just let students read themselves as the extracurricular interest. In the course of class, the class is just a time for understanding the text and checking the answers to the assigned questions or exercises.

C. The teacher ignores the cultivation of student's good study habits, especially the good habit of preparation before class, study in class and review after class.

D.There is no reasonable teaching plan or a complete set of readings. And the amount of reading teaching is not enough. On the premise of no quantitative change, qualitative change is unlikely to occur.

\section{Micro Lecture' Advantages and Characteristics}

Without multifarious course system, teaching target or teaching object, micro lectures are usually referred to as "fragmented" teaching with only one or two language points. The lectures,however, are targeted for specific target groups with the main purpose of transmitting specific knowledge contents, and micro though the lecture seems, it does have its own system and logic, conveying comprehensive knowledge. And the characteristics of the micro lecture are as follows:

A. The teacher's teaching. He or she can appear or not appear in the spectators' view.

B. The use of streaming media. The video and animation can be used based on streaming media network.

C. A short teaching time. Micro lectures mostly last 5-10 minutes. The shortest spans 1 to 2 minutes, and the longest no more than 20 minutes.

D.The teaching content. Micro lecture is mainly focused on a particular subject knowledge ; compared with complicated traditional classroom teaching contents, micro lectures' teaching contents are supposed to be a lot more refined.

E. A small resource capacity. Micro lectures' videos don’t occupy too much space, so they are suitable for study on mobile devices.

F. Classic demonstration case. Micro lectures use real, concrete, typical case teaching.

G. Autonomous learning preferred. Micro lectures are mainly for students' autonomous 
learning,so they are truly "one to one" teaching mode.

\section{Practical Application of Micro Lectures in English Reading Teaching}

With the advent of the $21^{\text {st }}$-century Micro Era, micro lectures arise at the historic moment. Micro lectures have been widely applied to English reading teaching process , for example, lead-in, key and difficult point explanation, post-class teaching expansion. The application of micro lectures has transformed the traditional classroom teaching modes and brought about energy to boring English reading classes, thus igniting the enthusiasm of the students' learning and improving the students' learning efficiency ${ }^{[4]}$.

A.Lesson review. In English reading, students need to learn and review the learned knowledge and consolidate new knowledge to achieve a solid basis. But each English reading lesson requires students to master a lot of vocabulary, grammar, syntax and discourse, so class time is not sufficient for students.Therefore, the teacher might as well make a micro lecture video designed for tackling with important and difficult teaching contents, and students can make use of their spare time to watch videos.

B. New lesson lead-in. As the saying goes, interest is the best teacher. English reading is at times so boring that students lack of learning enthusiasm, which is the main reasons for the poor efficiency in English reading teaching. Therefore, while leading in a new lesson, the teacher can elaborate videos and require the students to watch them to stimulate students' learning enthusiasm. For example, when we deal with a reading article entitled The Robot at Home in College English, before The formal lecture, teacher can play a video clip which tells the types and purposes of robots. Then the teacher can follow the video clip with the following questions: What kind of robot would you like if you can have one? Why? / What things can your robot do? Through the visual and auditory effects, students' interest is highly stimulated, thus successfully attracting all the attention of the students. During the process of video play, the students have surprised and delighted expression in their faces, which can help them actively participate in classroom study and discussion, and create an active classroom atmosphere beneficial to the grasp of knowledge quickly and well.

C. Teaching the difficulties. Micro lectures are micro in form, fine in content and beautiful in effect. A certain knowledge point needs only five minutes to be accurately explained.Using micro teaching in English reading teaching can convey a clear view of knowledge in the shortest time in the most effective way. In addition to the words, most students find it a big headache to learn English grammar and syntax. In order to solve this problem, we might as well summarize and analyze the various knowledge points and make them into micro video lectures to assist students to better master English grammar and syntax.

D. Autonomous learning. Xingzhi TAO , a famous Chinese educator, once said: "I think a good teacher means not teaching students knowledge but teaching students how to learn." Cultivating autonomous learning ability adapts to the situation of rapid development of modern science and technology and meeting the challenge of the new world development. As is stated in Learning to Be published by the UNESCO: the illiteracy of the future is not illiterate people, but those who don't know how to learn. Therefore, in today's era of knowledge explosion, using micro lectures in English reading teaching is necessary. Teachers have the micro video clips upload to the Internet for students to watch at any time, thus cultivating the learning ability of autonomous learning and fully mobilizing students' learning enthusiasm. In autonomous learning, students can choose to study according to their foundation and learning ability. They can suspend or replay micro lecture video at any time, so it can effectively help the students avoid missing or neglecting the knowledge that they don't understand.

Micro lectures play an important part in the whole teaching organization. It can't be separated from other teaching activities. The rise of micro lectures is the supplement and development of traditional teaching resources ${ }^{[5]}$. They facilitate students' autonomous learning after class, thus making up for the deficiency in classroom teaching. 


\section{Considerations in Applying Micro Lectures in English Reading Teaching}

As a new way of teaching, compared with the traditional way of teaching,micro lecture has many advantages, but we still need time and experience to constantly update and reform the teaching mode.In the application of micro lecture to the English reading teaching, we should pay attention to the following aspects.

A.Make the subject as accurate as possible. Not all the lessons and each knowledge point can be taught by means of micro lecture. Select the ones that need micro lectures to improve the efficiency.

B.Understand the theme as clearly as possible. Micro lectures are mainly focused on solving difficulties in teaching a certain knowledge point, rather than the whole text. So it is valuable and meaningful to considerately choose the theme .

C. Be attractive. In the teaching process, students are considered as the main body, so the micro lectures are supposed to be humorous and attractive, so as to seize the students' vision and attention and fully arouse the enthusiasm of their learning.

D.Be straightforward. Micro lecture is meant to teach the abstract content in the form of intuitive and concrete video images, which is to help the students spend the least time grasping the most knowledge.,

E. Be designed properly. One micro lecture is only for one knowledge point, so try to include informative messages in interpretation and certain questions in the teaching process. At the end of each lecture, there must be a brief summary to help students retrospect the contents and summarize main points, emphasis and difficulty.

F. Use and integrate various teaching resources. As a new teaching model and study way, because of the scattered and fragmentary interpretation and explanation of knowledge, teachers must integrate and use a variety of teaching resources in micro lectures to achieve good teacher-student interaction and optimize resources so as to guarantee the high quality of teaching,

G. Require higher quality and ability in the teachers. In the application of the micro lectures in English reading teaching, front-line teachers should be better equipped with professional quality as well as the computer technology proficiency.

\section{Conclusion}

Although the micro lecture is very likely to be one of leading teaching means in the future, it is impossible to replace the traditional classroom teaching activities. We must clearly recognize that English is a discipline with a lot of practice, so we must cultivate the students' English communicative skills via the extensive use of communication between teachers and students or between students. Due to the continuous development of modern educational teaching concept, English reading teaching mode and method are in constant innovation. Teachers should try to use micro lectures in teaching to assist the traditional classroom teaching and make full use of different teaching modes to help students improve the reading proficiency. This paper includes the characteristics of micro lectures and the application of micro lectures in English reading teaching, with the purpose of providing some practical reference to the English teachers. With the development of the society and the accumulation of the experience in the wide application of micro lectures in English reading teachers, the researches are bound to be deeper and maturer in the future.

\section{Acknowledgements}

Fund Projects: Scientific Research Project in Colleges and Universities Funded by Education Department of Hunan Province in 2015(No:15C0167) and Scientific Research Project Funded by Changsha Medical University in 2014 (No: KY201457).

\section{References}

[1] Tiesheng Hu, Micro Lecture: a New Trend of Developing the Regional Education Information Resources[J].Studies of Audio-visual Education,2011(10):62-64 
[2] Leming Liang, Research on Micro Lecture Design Pattern[J]. Open Education Research, 2013( 2):67-75.

[3] Na Yin, Let Multimedia into the English Classroom and Stimulate Students' Interest in Learning[J]. Chinese Education Technology and Equipment, 2013( 7):42-43.

[4] Xinyue Wang, Research on the Strategies of Teaching and Learning in English Reading Teaching[D] Hunan: Jishou University Thesis, 2013

[5] Haiyan Lu, Feasibility Analysis on the Application of Micro-class Based "Flipped Classroom”Mode in College English Teaching[J]. Computer-assisted Foreign Language Education, 2014(4):33-36.

[6] Jing Wang, Research on the Making and Application of Micro Lectures in College English[J]. Information and Computer, 2015(8):113-114 